\title{
Fecal-oral transmission of SARS-CoV-2: review of laboratory-confirmed virus in gastrointestinal system
}

\author{
Dajana Cuicchi ${ }^{1}$ (1) $\cdot$ Tiziana Lazzarotto $^{2} \cdot$ Gilberto Poggioli $^{1}$
}

Accepted: 9 October 2020 / Published online: 14 October 2020

(C) Springer-Verlag GmbH Germany, part of Springer Nature 2020

\begin{abstract}
Purpose The objective was to collect the data available regarding the presence of laboratory-confirmed severe acute respiratory syndrome coronavirus 2 (SARS-CoV-2) in gastrointestinal system and to evaluate whether the digestive system could contribute to viral transmission.

Methods Bibliographic databases were searched to identify all studies documenting, in adult patients with a confirmed diagnosis of coronavirus disease 2019 (COVID-19): (1) the presence of SARS-CoV-2 ribonucleic acid in the feces; (2) the presence of SARS-CoV-2 ribonucleic acid in the intestinal cells; (3) live SARS-CoV-2 in the feces.

Results Twenty seven met the inclusion criteria. In 26 studies, the presence or absence of SARS-CoV-2 ribonucleic acid in the feces of COVID-19 patients had been reported. Out of the 671 patients, $312(46.5 \%)$ had a positive stool sample for viral nucleic acid. Of these patients, $63.9 \%$ remained positive for viral nucleic acid in the feces after pharyngeal swabs became negative; Three studies also evaluated the viral ribonucleic acid in the gastrointestinal tissues and the presence of SARS-CoV-2 nucleic acid was found in samples of 3 patients out of 8 examined (37.5\%). The presence of the live virus in stool samples was confirmed in two studies but no in in a recent study from Germany. These results suggested that SARS-CoV-2 could infect gastrointestinal epithelial cells and it may be transmitted through the digestive tract.

Conclusion In order to control the pandemic, every effort should be made to understand all the possible routes of transmission of the infections, even the less important ones.
\end{abstract}

Keywords COVID-19 · Feces · Fecal-oral transmission $\cdot$ Gastrointestinal system $\cdot$ Severe acute respiratory syndrome coronavirus 2

"Sed domus corporibus exanimis, itinera funeribus complebantur; non sexus, non aetas periculo vacua; servitia perinde et ingenua plebes raptim extingui, inter coniugum et liberorum lamenta, qui dum adsident, dum deflent, saepe eodem rogo cremabantur." Annales XVI, 13 Tacito

Dajana Cuicchi

dajana.cuicchi@aosp.bo.it

1 Surgery of the Alimentary Tract, Department of Medical and Surgical Sciences, Sant'Orsola- Malpighi Hospital, Alma Mater Studiorum University of Bologna, Via Albertoni 15, 40138 Bologna, Italy

2 Operative Unit of clinical Microbiology, Department of Diagnostic Medicine and Prevention, Sant'Orsola Hospital, Alma Mater Studiorum University of Bologna, Via Albertoni 15, 40138 Bologna, Italy

\begin{abstract}
"Yet the houses were filled with lifeless bodies, the streets with funerals. Neither sex nor age gave immunity from danger; slaves and the free-born populace alike were summarily cut down, amid the laments of their wives and children, who, themselves infected while tending or mourning the victims, were often burnt upon the same pyre." Annals Book XVI, 13 Tacitus
\end{abstract}

\section{Introduction}

Since what would later be called severe acute respiratory syndrome coronavirus 2 (SARS-CoV-2) emerged for the first time in Wuhan, China, in December 2019, it has spread almost all over the world within a very short period of time and, on May 31, 2020, a total of 5,934,936 confirmed cases of coronavirus disease 2019 (COVID-19) including 367,153 deaths 
were reported [1]. The World Health Organization (WHO) declared the outbreak of COVID-19 an international public health emergency at the end of January and, deeply concerned by the alarming levels of spread and severity, it made the assessment that COVID-19 should be characterized as a pandemic on March 11, 2020.

SARS-CoV-2 is an enveloped, positively charged, singlestranded RNA virus belonging to the beta coronavirus genus; it is one of seven known coronavirus species responsible for human diseases [2]. The genome sequence of SARS-CoV-2 is $82 \%$ similar to severe acute respiratory syndrome coronavirus (SARS-CoV). Human coronaviruses, such as SARS-CoV and Middle East respiratory syndrome coronavirus (MERS-CoV), are known to cause respiratory and gastrointestinal (GI) symptoms $[2,3]$. Since it has been shown that both viruses can be excreted in the stools of infected patients and remain viable under conditions which could facilitate fecal-oral transmission, it is possible that SARS-CoV-2 could also be transmitted via this route [3]. Moreover, SARS-CoV-2 could use angiotensin-converting enzyme 2 (ACE2), the same receptor as SARS-CoV, to infect humans [4]; ACE2 is known to be abundant in the epithelia of the lungs and the intestine in humans which might add to the evidence of this possible route for COVID-19 [5]. In fact, although droplet and contact transmission are definitely the main routes of infection, studies regarding the presence of SARS-CoV RNA in the feces and in the colonic biopsy samples of infected patients have been published in recent months. Fecal-oral transmission poses very important public health implications and may partly explain the potential recurrence of the disease and its persistent transmission. Due to this concern, the authors sought to collect the data available and evaluate whether the digestive system could contribute to viral transmission.

\section{Methods}

\section{Eligibility criteria}

Peer-reviewed articles documenting the presence of live SARS-CoV-2 or viral RNA either in the feces or in the intestinal cells of patients with a confirmed diagnosis of COVID19 were included. The study population consisted of adult COVID-19 patients. Only studies in English were considered. Any study design was eligible; however, abstracts, review articles, and studies published on medRxiv and bioRxiv were excluded. Studies regarding patients without virological proof of SARS-CoV-2 infection were also excluded.

\section{Information sources and search strategy}

All articles published from December 2019 to May 31, 2020, in PubMed and in the Cochrane Library databases were consulted. The medical subject heading (MeSH) terms used for the research were: "coronavirus 2019", "COVID-19", "severe acute respiratory syndrome coronavirus 2 ", "SARSCoV-2"; different keywords were added to increase the sensitivity and specificity of the search (e.g., "pandemic", "epidemic", "outbreak", "digestive", "transmission", "infection"," enteric", "intestinal", "bowel", "feces", "stool", "transcriptase polymerase-chain-reaction", "biopsy"). Additional trials were identified by means of the accurate evaluation of the reference list of the studies included.

\section{Study selection}

The literature search was independently conducted by two authors to extract the relevant information. The results of the initial search strategy were first screened by title and abstract. The full texts of relevant articles were examined for inclusion and exclusion criteria (Fig. 1, PRISMA flow chart). When extracting information from the studies, the two researchers conferred to compare findings and reach a consensus. When a consensus was not reached, an independent researcher was consulted. The relevant information was then reported in a narrative review.

\section{Data collection process and data items}

Two investigators independently extracted, from the included studies, the following data: study authors, study designs, main results, and limitations.

\section{Results}

Twenty seven studies met the inclusion criteria [4, 6-31]. In 26 of all 27 studies, the presence or absence of SARS-CoV-2 RNA in the feces of COVID-19 patients had been reported (Table 1). The case-report regarding a COVID-19 patient with a positive result of viral nucleic acid in a fecal specimen and negative results on multiple pharyngeal and sputum samples was included [6]. The results of two studies conducted on COVID-19 patients who underwent detection of viral RNA in specimens from multiple sites including feces were also included $[7,30]$. However, the results were excluded from the analysis of both the total number of patients evaluated and the prevalence of the positivity of the fecal tests as, in both studies, only the total number of stool tests carried out was specified but not the number of patients tested. In three studies, the intestinal mucosa was analyzed. Two of these 3 studies revealed the presence of a viral nucleotide in gastrointestinal tissue samples in 7 patients; all three studies had also tested SARS-CoV-2 RNA in the feces [8, 9, 20]. In 3 studies, researchers tried to isolate the virus from stool samples $[7,10$, 11]. Two of these 3 studies had also tested SARS-CoV-2 


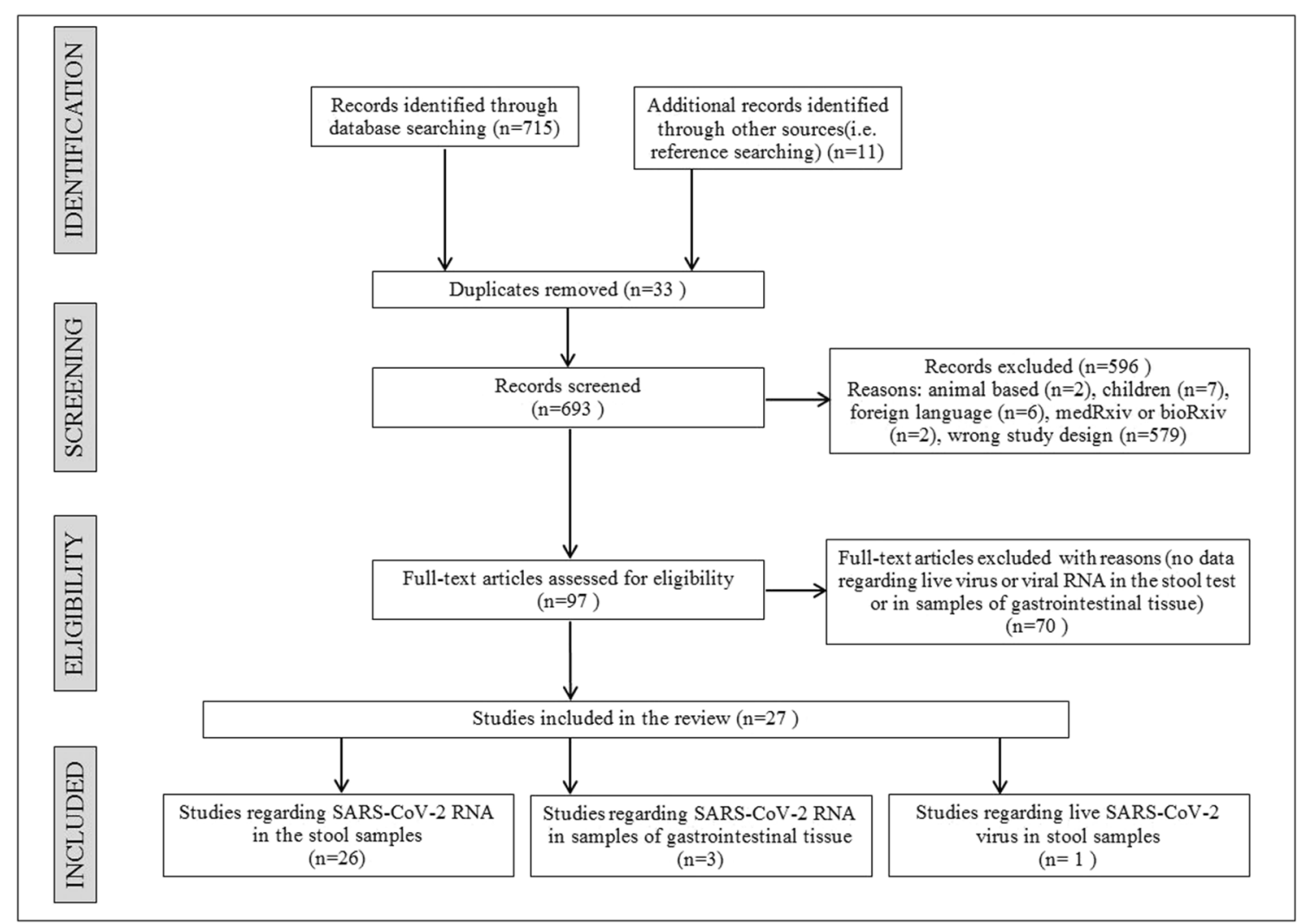

Fig. 1 Flow diagram of study selection

RNA in the feces. However, the study of Wolfel was excluded from the analysis of the rate of positive stool samples for viral RNA as it lacked some necessary information.

\section{SARS-CoV-2 RNA in the stool}

Overall, the authors evaluated data from 671 patients in order to determine the rate of viral shedding in the stool. Out of the 671 patients with laboratory-confirmed COVID-19, 312 (46.5\%) had a positive stool sample for viral RNA. Of these studies, the rate varied from 6.5 to $66.7 \%$. The cycle threshold $(\mathrm{Ct})$ value of the stool samples ranged from 22.3 to 38.4 (Table 1). In the majority of studies, the nucleic acid positivity in the fecal samples was not related to gastrointestinal symptoms and severity of illness [4, 7, 9, 12, 13]. Interestingly, Han et al. [14] found that patients presenting with digestive symptoms were more likely to test positive for viral RNA in fecal specimens $(73.3 \%$ vs. $14.3 \%, p=0.033)$. Similarly Wei et al. [29] found that the frequency of positive rate for testing SARS-CoV-2 from stool was higher in patients with diarrhea, as compared with patients without diarrhea at admission $(69 \%$ vs $17 \%, p<0.001)$. Moreover Chen et al. [31] found that the presence of viral RNA in the anal swab was positively correlated with the severe disease stage. Of 183 Covid-19 patients with SARS-CoV-2 RNA in stool specimens, 117 (63.9\%) remained positive for viral RNA in the feces after pharyngeal swabs became negative; the proportion varied from 10 to $81.8 \%$. The stool viral clearance was longer in patients with steroid use as compared to those without steroid use [15].

\section{SARS-CoV-2 RNA in samples of gastrointestinal tissue}

To investigate the clinical significance of SARS-CoV-2 RNA in feces, Xiao et al. [8] examined the viral RNA in the feces of 73 patients with Covid-19; they also evaluated both the viral RNA and the viral nucleocapsid protein in the gastrointestinal tissues of one of these patients. They found SARS-CoV-2 RNA and viral nucleocapsid protein in the cytoplasm of gastric, duodenal, and rectal glandular epithelial cells. Moreover, their immunofluorescent data showed that ACE2 protein, which has been proven to be a cell receptor for SARS-CoV2, was expressed in the cells of the gastric, duodenal, and rectal epithelia [8]. Lin et al. [9] also detected SARS-CoV-2 RNA in esophageal, gastric, duodenal, and rectal specimens in 2 out of 6 COVID-19 patients having gastrointestinal symptoms who underwent endoscopy. In this study, the presence of viral RNA in the gastrointestinal tissue was associated with severe disease; in fact, SARS-CoV-2 RNA was found in the samples of 2 patients with severe disease but not in those of 4 patients with nonsevere disease [9]. However in the case of SARS-CoV-2 gastrointestinal infection causing hemorrhagic colitis, histological examination of the colon and rectal 


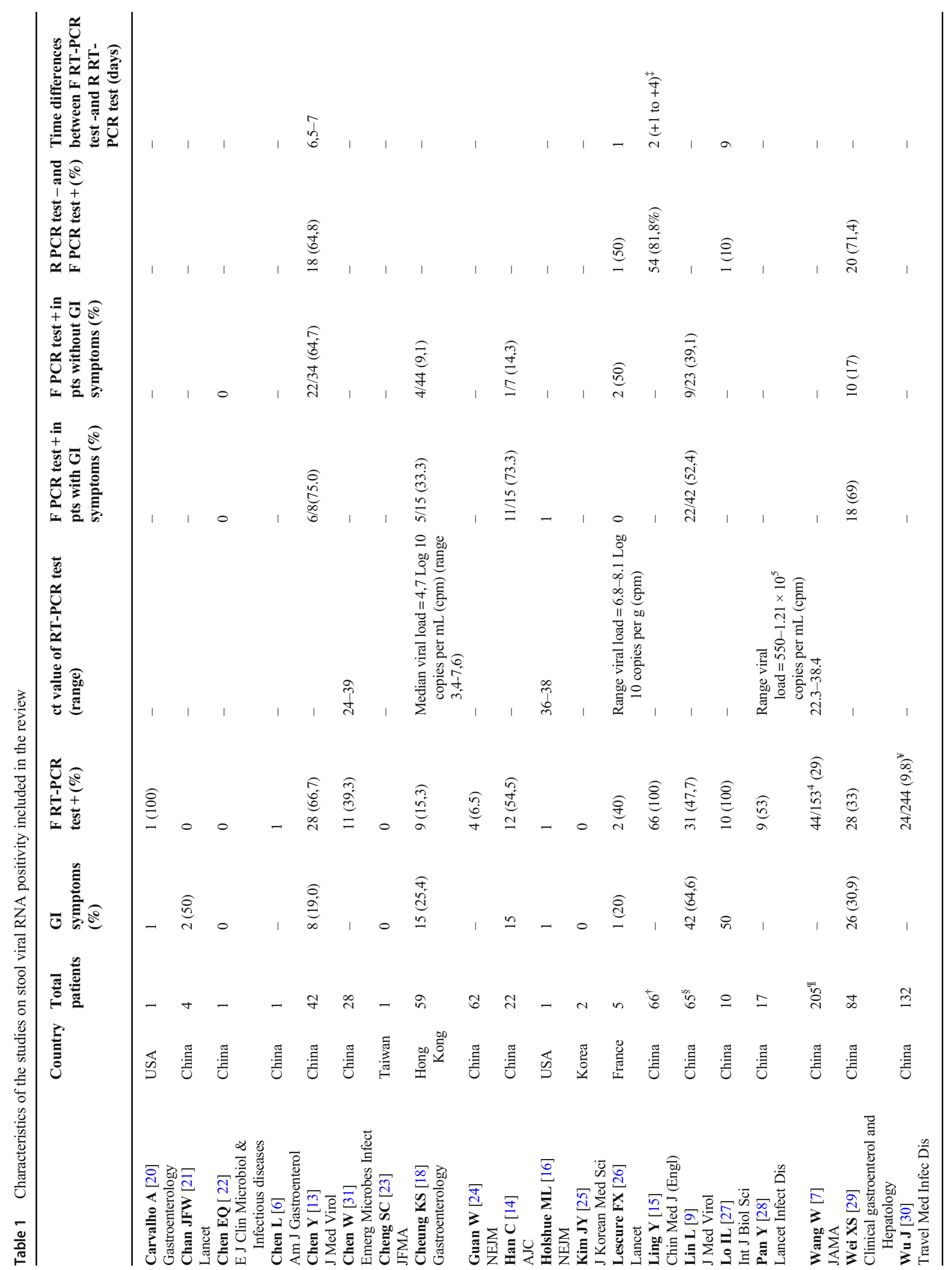




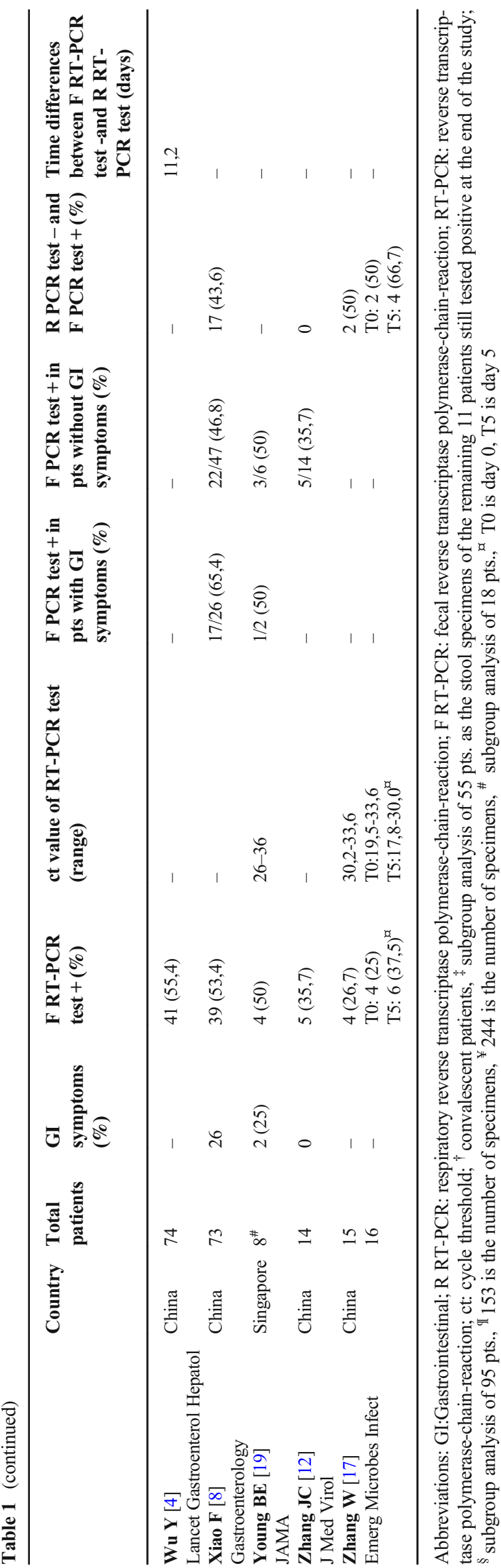

biopsies showed normal cellularity and intact crypts but did not show virocytes [20].

\section{Live SARS-CoV-2 virus in stool samples}

The presence of the live virus in stool samples from patients with COVID-19 was first confirmed by Zang et al. [10] using electron microscopy, they observed virus particles with the typical morphology of coronavirus after inoculating stool suspension into Vero cells. This finding was confirmed in another study in which 4 SARS-CoV-2 positive fecal specimens with high copy numbers were cultured. Live virus was observed in 2 cases under electron microscopy [7]. Instead, in a recent study from Germany, virus isolation from stool samples was never successful, irrespective of viral RNA concentrations, in 13 samples taken between day six and day twelve from four patients [11].

\section{Discussion}

Respiratory droplets and contact transmission are considered to be the most important transmission pathways of SARS$\mathrm{CoV}-2$ and, in fact, they are. However, these transmission routes could not fully explain the occurrence of all cases of COVID-19 and the rapid spread of the virus.

The finding of SARS-CoV-2 RNA in the stool of an American patient raised the question of the fecal-oral transmission route [16]. Subsequently, a growing number of clinical studies were conducted to verify the presence of viral nucleic acids in the stool samples of COVID-19 patients. The first molecular study of SARS-CoV-2 RNA in anal swabs of Covid-19-patients was conducted in Wuhan Pulmonary Hospital. The authors carried out two different investigations. The first one was conducted on 15 patients who still carried the virus following days of medical treatment. The authors found that the anal swabs of 4 patients were positive (26.7\%), and of these 4 patients, 2 had negative oral swabs. The aim of the second investigation was to determine the dynamic changes in viral presence in both the oral and the anal swabs in another group of 16 patients. The authors found more anal swab positives $(6 / 8,75 \%)$ than oral swab positives $(4 / 8,50 \%)$ in a later stage of infection [17]. High positivity rates for SARS-CoV-2 RNA in fecal specimens were also detected in subsequent studies with values ranging from 15.3 to $66.7 \%[4,7-9,12-14,18-20,26-29,31]$. Considering all the patients analyzed in this review, $46.5 \%$ had a positive stool sample for viral RNA. In contrast to the Ct value of 36-38 of the stool samples from the first US case, the $\mathrm{Ct}$ values in subsequent studies were, for the most part, below 34 . This suggested that viral shedding from the gastrointestinal tract could be abundant [7, 16-19, 31]. The studies available also demonstrated that a nonnegligible percentage of 
patients continued to have positive fecal tests while their respiratory specimens were negative [2-27, 29]. In a study of 66 convalescent patients, viral RNA in both oropharyngeal swabs and feces became negative at the same time in 12 cases $(18.2 \%)$; in the remaining 54 patients $(81.8 \%)$, the stool specimens became negative after a longer period of time than the throat swabs [15]. After the negative conversion of pharyngeal swabs, the duration of viral shedding from the feces varied from 2 to 11 days, regardless of COVID-19 severity [4, 13, 15, 27, 29]. In particular, one patient had positive stool samples for 33 days continuously after respiratory samples became negative [4]. Cheung et al. [18] reported data from a cohort of 59 patients with COVID-19 in Hong Kong; they carried out a systematic review and meta-analysis of 11 studies regarding the detection of the virus in the stool in a heterogeneous population of adults and children. They found similar results to those in the present study; RNA viral shedding in the stool was detected in $48.1 \%$ of patients, and $70.3 \%$ of these patients had persistent positive stool viral RNA, despite negative respiratory samples [18].

The mere presence of SARS-CoV-2 RNA in the stools of infected patients is not, however, sufficient to demonstrate virus infectivity by means of the fecal-oral route. In fact, it is uncertain whether these nucleic acids are live virus particles or just RNA fragments released from the intestinal cells. Stronger, though more limited, evidence derives from the detection of virus nucleotides in the samples of gastrointestinal tissue of COVID-19 patients [8, 9]. These results suggested that SARS-CoV-2 could infect gastrointestinal epithelial cells.

Recently, the isolation of three cases of infectious SARSCoV-2 viruses from stool samples of COVID-19 patients has directly proven that SARS-CoV-2 could be transmitted via fecal-oral route $[7,10]$. Nevertheless, live virus was not isolated from stool samples in 4 patients in spite of very high virus RNA concentrations in the stool and the occasional detection of viral subgenomic messenger RNAs directly in the clinical samples, factors which would indicate active replication in the gastrointestinal tract [11].

These results are preliminary and have some limitations; the majority of the data are from only one country, China, since the initial epicenter for this outbreak was this region; the analyses reported are mostly retrospective, single-center series with few cases or case reports. The viral shedding in the feces was not the primary aim in the studies analyzed. The heterogeneity was not formally assessed. Although only studies relating to adult population were analyzed, the studies are heterogeneous for type of sample (fecal specimens and anal swabs), sample timing, and follow-up testing. Nevertheless, this is currently the review with the largest number of articles relating to laboratory-confirmed virus in gastrointestinal system in adult population. This evidence has suggested that SARS-CoV-2 may be transmitted through the digestive tract. Although additional studies are needed to confirm fecal-oral transmission, this possibility should be taken into consideration because it has several implications. First, more attention should be paid to the five "F" factors of the fecal-oral route: fingers, flies, fields, fluids, and food. Hand cleansing with soap and disinfectants is frequently the better way to prevent transmission. Suggestions should however include maintaining environmental and personal hygiene, drinking mineral or boiled water, and avoiding raw food consumption. Strict precautions must be observed when handling the stools, vomitus, other bodily fluids, and stoma of infected patients or when disinfecting the environments of patients in medical facilities. In fact, the discharge into the toilet of feces of COVID-19 patients can generate infective aerosols which can lead to fomite transmission. The sewage of hospitals and houses of COVID-19 patients may serve as a source of infection. Rigorous protective measures are important to avoid crossinfection during endoscopic examination in epidemic areas. In the same way in the surgical theater is crucial that staff are properly trained and in particular they use appropriate tools and follow recommendations strictly to avoid increasing the risk of contamination. Both laparoscopic or open surgical procedures in fact, may potentially cause aerosolization of the virus and therefore infection of the personnel, probably even in absence of intestinal perforation or ischemia, due to presence of SARS-CoV-2 in peritoneal fluids [32-35]. The major concern is, however, the potential recurrence of the disease and persistent transmission from treated patients who meet discharge criteria with 2 sequential negative oropharyngeal swab tests collected $24 \mathrm{~h}$ apart since the clearance of viral RNA in patient stools is delayed as compared to oropharyngeal swabs. After discharge, the patient should pay close attention to hand hygiene and try to avoid sharing toilets with family members. Moreover a test for fecal nucleic acid could be useful to understand when to discontinue precautions.

SARS-CoV-2 probably has many routes of transmission which could explain its strong and rapid spread. In order to control the pandemic, every effort should be made to understand all the possible routes of transmission of the infections, even the less important ones. More studies regarding gastrointestinal involvement and viral excretion in feces are required.

Authors' contributions D.C.: conceptualized and designed the study in partnership with T.L. and P.G., conducted the literature search, collected data, carried out the initial analyses, and drafted the initial manuscript; T.L.: conceptualized and designed the study in partnership with D.C. and P.G., conducted the literature search, collected data, carried out the initial analyses, made substantial contributions to all aspects of the writing of the manuscript, which included contribution to conception, design, analysis and interpretation of the article, and review and revision of the manuscript. P.G.: conceptualized and designed the study in partnership with D.C. and T.L., interpreted data, reviewed and revised the manuscript, and supervised and provided mentorship throughout all stages of the project and writing of the manuscript.

Data availability Bibliographic databases. 


\section{Compliance with ethical standards}

Conflict of interest The authors declare that they have no conflict of interest.

Ethics approval Not applicable.

Consent to participate Not applicable.

Consent for publication Not applicable.

Code availability Not applicable.

\section{References}

1. World Health Organization, coronavirus Disease 2019 (COVID19) Situation Report-86 (WHO,2020); Available from: https:// www.who.int/docs/default-source/coronaviruse/situation-reports/ 20200415-sitrep-86-covid-19.pdf?sfvrsn=c615ea20_6

2. Gao QY, Chen YX, Fang JY (2020) 2019 novel coronavirus infection and gastrointestinal tract. J Dig Dis 21:125-126

3. Chan JF, Kok KH, Zhu Z et al (2020) Genomic characterization of the 2019 novel human-pathogenic coronavirus isolated from a patient with atypical pneumonia after visiting Wuhan. Emerg Microbes Infect 9:221-236

4. Wu Y, Guo C, Tang L, Hong Z, Zhou J, Dong X, Yin H, Xiao Q, Tang Y, Qu X, Kuang L, Fang X, Mishra N, Lu J, Shan H, Jiang G, Huang X (2020) Prolonged presence of SARS-CoV-2 viral RNA in faecal samples. Lancet Gastroenterol Hepatol 5:434-435

5. Zhang H, Kang Z, Gong H (2020) The digestive system is a potential route of 2019-nCov infection: a bioinformatics 2 analysis based on single-cell transcriptomes. bioRxiv. https://doi.org/10.1101/ 2020.01.30.927806

6. Chen L, Lou J, Bai Y, Wang M (2020) COVID-19 disease with positive fecal and negative pharyngeal and sputum viral tests. Am J Gastroenterol 115:790

7. Wang W, Xu Y, Gao R et al (2020) Detection of SARS-CoV-2 in different types of clinical specimens. JAMA 323:1843-1844

8. Xiao F, Tang M, Zheng X, Liu Y, Li X, Shan H (2020) Evidence for gastrointestinal infection of SARS-CoV-2. Gastroenterology 158:1831-1833

9. Lin L, Jiang X, Zhang Z, Huang S, Zhang Z, Fang Z, Gu Z, Gao L, Shi H, Mai L, Liu Y, Lin X, Lai R, Yan Z, Li X, Shan H (2020) Gastrointestinal symptoms of 95 cases with SARS-CoV-2 infection. Gut 69:997-1001

10. Zhang Y, Chen C, Zhu S et al (2020) Isolation of 2019-nCoV from a stool specimen of a laboratory confirmed case of the coronavirus disease 2019 (COVID-19). CCDC Weekly 2:123-124

11. Wölfel R, Corman VM, Guggemos W, Seilmaier M, Zange S, Müller MA, Niemeyer D, Jones TC, Vollmar P, Rothe C, Hoelscher M, Bleicker T, Brünink S, Schneider J, Ehmann R, Zwirglmaier K, Drosten C, Wendtner C (2020) Virological assessment of hospitalized patients with COVID-2019. Nature 581:465469

12. Zhang JC, Wang S, Xue Y Fecal specimen diagnosis 2019 novel coronavirus-infected pneumonia. J Med Virol 92:680-682

13. Chen Y, Chen L, Deng Q, Zhang G, Wu K, Ni L, Yang Y, Liu B, Wang W, Wei C, Yang J, Ye G, Cheng Z (2020) The presence of SARS-CoV-2 RNA in feces of COVID-19 patients. J Med Virol 92:833-840

14. Han C, Duan C, Zhang S, et al. (2020) Digestive symptoms in COVID-19 patients with mild disease severity clinical presentation, stool viral RNA testing, and outcomes. Am J Gastroenterol. https:// doi.org/10.14309/ajg.0000000000000664

15. Ling Y, Xu SB, Lin YX et al (2020) Persistence and clearance of viral RNA in 2019 novel coronavirus disease rehabilitation patients. Chin Med J (Engl) 133:1039-1043

16. Holshue ML, DeBolt C, Lindquist S et al (2020) First case of 2019 novel coronavirus in the United States. N Engl J Med 5(382):929936

17. Zhang W, Du RH, Li B et al (2020) Molecular and serological investigation of 2019-nCoV infected patients: implication of multiple shedding routes. Emerg Microbes Infect 9:386-389

18. Cheung KS, Hung IF, Chan PP, et al. (2020) Gastrointestinal manifestations of SARS-CoV-2 infection and virus load in fecal samples from the Hong Kong Cohort and systematic review and metaanalysis. Gastroenterology. https://doi.org/10.1053/j.gastro.2020. 03.065

19. Young BE, Ong SWX, Kalimuddin S, Low JG, Tan SY, Loh J, Ng OT, Marimuthu K, Ang LW, Mak TM, Lau SK, Anderson DE, Chan KS, Tan TY, Ng TY, Cui L, Said Z, Kurupatham L, Chen MIC, Chan M, Vasoo S, Wang LF, Tan BH, Lin RTP, Lee VJM, Leo YS, Lye DC, for the Singapore 2019 Novel Coronavirus Outbreak Research Team (2020) Epidemiologic features and clinical course of patients infected with SARS-CoV-2 in Singapore. JAMA 323:1488-1494

20. Carvalho A, Alqusairi R, Adams A, et al. (2020) SARS-CoV-2 Gastrointestinal infection causing hemorrhagic colitis: implications for detection and transmission of COVID-19 Disease Am J Gastroenterol. https://doi.org/10.14309/ajg.0000000000000667

21. Chan JFW, Yuan S, Kok KH et al (2020) A familial cluster of pneumonia associated with the 2019 novel coronavirus indicating person-to-person transmission: a study of a family cluster. Lancet 395:514-523

22. Chen EQ, Wang LC, Tang GM, Yang Y, Wang MJ, Deng R, Chen F, Wang ML, Tao YC, Feng P, Tang H (2020) Brief report of the first cured 2019-nCoV pneumonia patient in West China hospital. Eur J Clin Microbiol Infect Dis 27:1-3. https://doi.org/10.1007/ s10096-020-03866-Z

23. Cheng SC, Chang YC, Chiang YLF et al (2020) First case of coronavirus disease 2019 (COVID-19) pneumonia in Taiwan. J Formos Med Assoc 119(3):747-751

24. Guan WJ, Ni Z, Hu Y et al (2020) Clinical characteristics of coronavirus disease 2019 in China. N Engl J Med 382:1708-1720

25. Kim JY, Ko JH, Kim Y et al (2020) Viral load kinetics of SARSCoV-2 infection in first two patients in Korea. J Korean Med Sci 35: -e86

26. Lescure FX, Bouadma L, Nguyen D et al (2020) Clinical and Virological data of the first cases of COVID-19 in Europe: a case series. Lancet Infect Dis 6:697-706

27. Lo IL, Lio CF, Cheong HH, Lei CI, Cheong TH, Zhong X, Tian Y, Sin NN (2020) Evaluation of SARS-CoV-2 RNA shedding in clinical specimens and clinical characteristics of 10 patients with COVID-19 in Macau. Int J Biol Sci 16:1698-1707

28. Yang P, Zhang D, Yang P, Leo L, Poon M, Wang Q (2020) Viral load of SARS-CoV-2 in clinical samples. Lancet Infect Dis 20:411412

29. Wei XS, Wang X, Niu YR et al (2020) Diarrhea is associated with prolonged symptoms and viral carriage in corona virus disease 2019. Clin Gastroenterol Hepatol S1542-3565(20):30526-30527. https://doi.org/10.1016/j.cgh.2020.04.030

30. Wu J, Liu J, Li S et al (2020) Detection and analysis of nucleic acid in various biological samples of COVID-19 patients. Travel Med Infect Dis 101673. https://doi.org/10.1016/j.tmaid.2020.101673 Online ahead of print

31. Chen W, Lan Y, Yuan X et al (2020) Detectable 2019-nCoV viral RNA in blood is a strong indicator for the further clinical severity. Emerg Microbes Infect 9:469-473 
32. Coccolini F, Perrone G, Chiarugi M, di Marzo F, Ansaloni L, Scandroglio I, Marini P, Zago M, de Paolis P, Forfori F, Agresta F, Puzziello A, D’Ugo D, Bignami E, Bellini V, Vitali P, Petrini F, Pifferi B, Corradi F, Tarasconi A, Pattonieri V, Bonati E, Tritapepe L, Agnoletti V, Corbella D, Sartelli M, Catena F (2020) Surgery in COVID-19 patients: operational directives. World J Emerg Surg 15:25

33. Flemming S, Hankir M, Hering I, Meybohm P, Krone M, Weissbrich B, Germer CT, Wiegering A (2020) Abdominal fluid samples (negative for SARS-CoV -2) from a critically unwell patient with respiratory COVID -19. BJS 107:e259-e260
34. Coccolini F, Tartaglia D, Puglisi A, Giordano C, Pistello M, Lodato M, Chiarugi M (2020) SARS-CoV-2 is present in peritoneal fluid in COVID-19 patients. Ann Surg 272:e240-e242

35. Saeed S, Hossein K, Nasser Malekpour A et al (2020) Abdominal surgery in patients with COVID-19. Detection of SARS-CoV-2 in abdominal and adipose tissues. Ann Surg. https://doi.org/10.1097/ SLA.0000000000004165

Publisher's note Springer Nature remains neutral with regard to jurisdictional claims in published maps and institutional affiliations. 